\title{
DIFERENTES PADRÕES DE MEDIAÇÃO E SUAS REPERCUSSÕES NAS APRENDIZAGENS DOS ALUNOS
}

\author{
DIFFERENT MEDIATION PATTERNS AND THEIR \\ REPERCUSSIONS ON STUDENT LEARNING
}

\author{
DIFERENTES ESTÁNDARES DE MEDIACIÓN Y SUS \\ REPERCUSIONES EN EL APRENDIZAGE DEL ALUMNO
}

Maria Júlia Branco

Escola Secundária de Póvoa de Lanhoso. Portugal.

\begin{abstract}
Resumo Analisaram-se, por três anos consecutivos, as práticas de ensino de dois professores de Física e Química, tendo como referência as práticas de ensino de um professor mais experiente. Pretendia-se levar esses dois professores a refletirem nas suas práticas de ensino, no sentido de melhorarem-nas, de modo a promoverem aprendizagens mais eficazes nos seus alunos. Este estudo decorreu durante três fases distintas, mas que se complementam: a $1^{\mathrm{a}}$. e $3^{\mathrm{a}}$. fases são consideradas de fases avaliativas; a $2^{\mathrm{a}}$. fase é de intervenção direta com a participação do investigador no sentido de ajudar os professores a refletirem nas suas práticas, tendo como suporte narrações multimodais das suas aulas e ferramentas de ajuda. Desse modo, as duas primeiras fases correspondem a um ciclo completo de investigação-ação. No decorrer deste estudo, foram identificados nove padrões de mediação, denominados de E1 a E9, de acordo com a qualidade crescente dos mesmos. Verificou-se que a mediação do professor, nomeadamente no modo como apresenta a tarefa e utiliza os mediadores, é determinante para envolver os alunos em atividades sociais de produção, comunicação e avaliação do conhecimento científico, ou seja, em práticas epistêmicas.

Palavras-chave: Padrões de mediação; Práticas epistêmicas; Narração multimodal; TaREFA; REFLEXÃO.
\end{abstract}


Abstract During three consecutive years, the teaching practices of two Physics and Chemistry teachers were analysed, with reference to the teaching practices of a more experienced teacher. It was intended to lead these two teachers to reflect on their teaching practices in order to improve them in order to promote more effective learning in their students. This study was carried out during three distinct phases, but they complement each other: the 1st and 3rd phases are considered as evaluation phases; the second phase is a direct intervention with the researcher's participation in helping teachers to reflect on their practices, having as support multimodal narrations of their classes and aiding tools. In this way, first and two phases correspond to a complete cycle of action research. During this study, 9 patterns of mediation were identified, named E1 to E9 according to their increasing quality. It was verified that teacher mediation, especially in the way it presents the task and uses the mediators, is determinant to involve students in social activities of production, communication and evaluation of scientific knowledge, that is, in epistemic practices.

Keywords: Patterns of mediation; Epistemic practices; Multimodal narration; Task; REFLECTION.

Resumen Se analizaron durante tres años consecutivos las prácticas de enseñanza de dos profesores de Física y Química, teniendo como referencia las prácticas de enseñanza de un profesor más experimentado. Se pretendía llevar a estos dos profesores a reflexionar en sus prácticas de enseñanza para mejorarlas para promover aprendizajes más eficaces en sus alumnos. Este estudio se desarrolló durante 3 fases distintas, pero que se complementan: la $1^{\mathrm{a}}$. y $3^{\mathrm{a}}$. fase son consideradas de fases evaluativas; la segunda fase es de intervención directa, con la participación del investigador en el sentido de ayudar a los profesores a reflexionar en sus prácticas, teniendo como soporte narraciones multimodales de sus clases y herramientas de ayuda. De este modo, las dos primeras fases corresponden a un ciclo completo de investigación-acción. Durante este estudio se identificaron 9 estándar de mediación, denominados de E1 a E9, de acuerdo con la calidad creciente de los mismos. Se verificó que la mediación del profesor, especialmente en el modo como presenta la tarea y utiliza los mediadores, es determinante para involucrar a los alumnos en actividades sociales de producción, comunicación y evaluación del conocimiento científico, es decir, en prácticas epistémicas.

Palabras clave: Estándares de mediación; Prácticas epistémicas; Narración multimoDAL; TAREA; REFLEXIÓN.

\section{INTRODUÇÃo}

Pretende-se, com este trabalho, identificar padrões de mediação promotores de práticas epistêmicas (PE) nos alunos. Todavia, a promoção de PE, definidas por Kelly e colegas (2012) como atividades sociais de produção, comunicação e avaliação do conhecimento, não é uma tarefa fácil nem linear para o professor. A mediação que o professor utiliza na 
sala de aula (LOPES et al., 2010, b) é determinante para esse fim, pois as práticas de ensino do professor são de importância crucial para a qualidade das aprendizagens dos alunos. Acontece que, muitas vezes, os professores desconhecem o impacto que as suas práticas têm nessas aprendizagens. A narração multimodal (NM) (LOPES et al., 2014), usada como instrumento de recolha e organização de dados, permite ao professor tomar consciência de determinados aspectos relacionados com a sua própria prática que carecem de mudança ou de evolução, no sentido de melhorar as aprendizagens dos seus alunos (LOPES et al., 2012). O professor precisa tomar consciência das suas práticas de ensino e refletir a respeito delas uma vez que o ato de refletir sobre a prática profissional, sendo um instrumento de aprendizagem poderoso, é ainda um forte catalisador do desenvolvimento profissional (SCHÖN, 1983; ALARCÃO, 1996; BUTLER et al., 2004; GILLENTINE, 2006). A reflexão acerca da ação é considerada um recurso importante para a formação e aperfeiçoamento profissional dos professores, pois, durante a prática o professor tem necessidade de tomar decisões para resolver os problemas que vão surgindo ou fluindo no decorrer da ação (SACRISTÁN, 1988). Assim, ao promover as suas capacidades criativas e reflexivas, os professores melhoram as suas práticas (BREDESON, 2002) nos aspectos em que a sua mediação é determinante, uma vez que a ocorrência de PE está intimamente relacionada com as práticas de ensino potenciadas pelo professor (p.e.: SCOTT et al., 2006; CRAWFORD et al., 2000; LOPES, BRANCO, \& JIMÉNEZ-ALEIXANDRE, 2011).

Neste trabalho, constata-se (BRANCO, 2018a,c) que um dos aspectos cruciais a ter em conta é a escolha de tarefas adequadas, bem como, a sua condução em sala de aula. As tarefas definem situações práticas sobre as quais o professor precisa refletir (SACRISTÁN, 1988). Além do mais, a tarefa apresentada (trabalho solicitado ao aluno, a realizar em determinado tempo, como resposta a uma questão ou a outro pedido) nem sempre coincide com a atividade que os alunos realmente fazem (LOPES et al., 2008). O envolvimento dos alunos tanto em práticas próximas do conhecimento sensorial (PE tipo 1), como em práticas mais próximas do conhecimento teórico (PE tipo 3) ou em práticas intermédias (PE tipo 2), pode (ou não) ser facilitado pelo uso de artefatos mediadores (BRANCO, 2018a,c). Quando os mediadores possuem existência material (são trabalháveis e manipuláveis), permitem a aprendizagem autorregulada. Como exemplo, se referem a objetos, simulações e representações gráficas ou simbólicas, que são considerados mediadores epistêmicos (KNUUTTILA, 2005). Esses mediadores potenciam outras ações além da interpretação das linguagens e códigos representados (RADFORD, 2012), ou seja, facilitam a realização de ações e operações, mobilizando não só o valor simbólico como o operacional (WILSON, 2013; WU \& PUNTAMBEKAR, 2012). Quando os mediadores são instrumentos psicológicos de mediação, por exemplo, conceitos, analogias e perguntas, permitem organizar a informação para comunicar, argumentar, explicitar relações entre estruturas ou defender uma ideia. Nesses casos, são considerados mediadores simbólicos (DANISH \& ENYEDY, 2007; REVELES, et al., 2007). O modo como o professor usa os mediadores, quer epistêmicos quer simbólicos, é de extrema importância para a ocorrência (ou não) de PE diversificadas e frequentes (BRANCO, 2018a,c). 
Neste trabalho, se identificaram nove padrões de mediação tendo em conta as práticas de ensino dos professores, as características das tarefas apresentadas e o modo como o professor as conduz, de forma a inferir quais os padrões que promovem PE mais frequentes e diversificadas.

Consideram-se padrões de mediação de qualidade superior aqueles onde o professor apresenta práticas de ensino que promovem práticas epistêmicas diversificadas e consistentes nos seus alunos, durante a execução da tarefa exibida.

\section{Problema de investigaÇão}

Já foi referido que a aprendizagem da Ciência implica o envolvimento dos alunos em PE (KELLY, 2005), que têm a ver com a forma como os alunos se envolvem em métodos científicos para construírem o conhecimento científico (LOPES et al., 2010a, 2010b), onde a mediação do professor assume um papel determinante (BRANCO, 2018a,c).

Levar o professor a sentir a necessidade de adaptar (ou mudar) determinados traços da sua mediação para conseguir promover essas aprendizagens junto dos seus alunos é o problema que este trabalho se propõe a dar resposta.

Como tal, pretende-se com este trabalho promover em dois professores a necessidade de adaptar a sua mediação às necessidades dos alunos no sentido de envolvê-los em práticas dessa natureza. Teve-se como referência a mediação de um professor mais experiente por ser uma pessoa com mais vivência em investigação didática e membro de um projeto de investigação comum, do qual se conhecia possuir práticas de ensino de elevada qualidade e diferentes das práticas dos professores A e B (BRANCO, 2018a, c).

O objetivo é identificar padrões de mediação desses três professores e inferir de que modo esses padrões se repercutem nas aprendizagens dos alunos em termos de ocorrência de PE. Pretende-se ainda levar esses professores a refletirem nas suas práticas de ensino, recorrendo a NM das suas aulas, de modo a lhes suscitar a vontade de as melhorarem com vista a apresentarem padrões de mediação de qualidade superior, nomeadamente no que diz respeito às características das tarefas exibidas e sua condução em sala de aula, tendo sempre como objetivo a promoção de PE frequentes e diversificadas.

\section{Metodologia}

Desenvolveu-se uma investigação de natureza qualitativa, de casos múltiplos (STAKE, 2013), mais concretamente três professores (A, B e C) de Física e Química que lecionavam $3^{\circ}$. ciclo e ensino secundário e respectivos alunos. O estudo decorreu em três anos consecutivos denominados de fases que, apesar de transcorrerem em anos diferentes, se complementam. As práticas de ensino do professor $\mathrm{C}$ nos serviram de referência, por ser uma pessoa com experiência em investigação e membro de um projeto de investigação comum, o qual teria, à partida, práticas de ensino com características distintas das características dos professores A e B. 
$\mathrm{Na} 1^{\text {a }}$. fase foram recolhidos todos os dados necessários para a elaboração de NM sem observação direta (BRANCO, 2018a,b,c; BRANCO et al. 2009) e sem qualquer intervenção pela parte do investigador. Todos esses dados foram organizados e analisados no sentido de identificar os padrões de mediação de cada professor nomeadamente no que concerne à apresentação e características das tarefas, nas práticas de ensino dos professores e sua repercussão nas PE dos seus alunos. Ou seja, a $1^{\text {a }}$. fase é considerada uma fase avaliativa.

A $2^{\mathrm{a}}$. fase teve início com a apresentação dos resultados preliminares relativos à $1^{\mathrm{a}}$. fase, baseando-nos nas respectivas NM. Discutiram-se esses resultados com os professores A e B relativamente aos seus padrões de mediação e suas repercussões na promoção de PE nos seus alunos, tendo como base os padrões de mediação obtidos com o professor $\mathrm{C}$, uma vez que as práticas de ensino desse professor (com mais experiência) nos serviram de referência.

Essa discussão, tendo sempre como base as respectivas narrações NM, suscitou nesses professores a necessidade de refinarem as suas mediações, escolherem tarefas mais desafiadoras para os seus alunos, adaptarem práticas de ensino mais eficazes tanto ao nível da condução da tarefa aos alunos como em práticas de ensino promotoras de PE. Reconheceram terem dificuldades em efetuarem essas mudanças pelo que pediram ajuda no sentido de conseguirem vencer esses constrangimentos. Com vista a ajudá-los nessas dificuldades foram-lhes cedidas e explicadas as ferramentas de ajuda produzidas por Lopes e colegas (2012) relativas a diversas dimensões da mediação, pedindo-lhes que prestassem atenção especial à ferramenta de ajuda relacionada com o trabalho solicitado ao aluno e às $\mathrm{PE}$ (BRANCO, 2017), uma vez que estas eram centrais ao foco deste trabalho. Pretendíamos, pois, que esses professores sentissem necessidade de recorrer a essas ferramentas (potenciada pela reflexão das suas práticas, espelhadas nas narrações multimodais), não só para a planificação das suas aulas, mas também para a sua gestão e envolvimento dos alunos em práticas epistêmicas consistentes e diversificadas.

Durante essa fase do estudo, toda vez que os professores apresentavam alguma dúvida na implementação das ferramentas de ajuda, o investigador intervinha no sentido dos esclarecimentos julgados pertinentes, encaminhando-os para excertos das suas NM que elucidassem as características da mediação a melhorar e para a ferramenta de ajuda julgada pertinente para esse efeito sem, contudo, interferir nas suas mediações. Pretendia-se com essa intervenção levar o professor a uma reflexão crítica das suas próprias práticas, refletidas nas NM da fase anterior, de modo a planificar e escolher estratégias que lhes permitissem atuar de modo diferente e mais eficaz na condução das tarefas apresentadas. Procedeu-se assim a um ciclo de investigação-ação (COHEN et al., 2013) composto pelas etapas de planificação (da aula); ação (a aula, em si); observação, avaliação e autoavaliação (identificação de aspectos da mediação que correram menos bem); reflexão (reflexão e alteração dos aspectos de mediação julgados necessários para a promoção de PE nos seus alunos). Nessa fase, procedeu-se à nova recolha de dados para a elaboração das NM relativas a esse ano de implementação.

A $3^{\mathrm{a}}$. fase do estudo teve início com a apresentação e discussão dos resultados preliminares obtidos na fase anterior, tendo como suporte as respectivas NM. Nessa fase, 
semelhantemente à $1^{\mathrm{a}}$. fase do estudo, não houve qualquer intervenção do investigador no sentido de interferir com a mediação dos professores envolvidos. Procedeu-se novamente à recolha dos dados necessários para a elaboração das NM relativas a essa fase do estudo para inferir acerca da consistência (ou não) das mudanças efetuadas nas práticas de ensino dos professores envolvidos relativamente às características do trabalho solicitado aos alunos e sua implementação, bem, como à promoção de práticas epistêmicas.

A análise desses dados, feita a partir das NM, decorreu em cinco etapas distintas. Na primeira etapa, analisaram-se as dimensões de análise em estudo em excertos das NM (trabalho solicitado ao aluno, suas características, práticas de ensino dos professores e práticas epistêmicas dos alunos), na totalidade de todos os professores intervenientes; na segunda etapa, categorizaram-se as NM por meio do programa NVivo8 ${ }^{\circledR}$, por intermédio de uma open code para identificar as categorias existentes em todas as NM. Essa análise foi realizada, inicialmente, em apenas alguns excertos das NM. Posteriormente, procedeu-se do mesmo modo para todas as NM referidas. Durante esse processo, houve necessidade de redefinir algumas categorias, definir novas que iam surgindo, fixá-las, e validá-las convenientemente; na terceira etapa, elaboraram-se os diagramas de interação (interação professor-aluno ou aluno-aluno) relativas às dimensões de análise em estudo, sendo cada diagrama iniciado com a apresentação da tarefa e respectivas características e terminado com a conclusão da mesma; na quarta etapa, analisaram-se todos os diagramas de interações, relativos à totalidade das NM, de modo a identificar padrões de mediação semelhantes no que concerne às práticas de ensino dos professores, às características dos trabalhos solicitados e às práticas epistêmicas dos alunos. Nessa análise, recorremos ao software STATISTICA (Statsoft $\AA$ ), por meio do qual se elaboraram dendrogramas relativos a todos os dados, de forma a identificar os padrões de mediação existentes por intermédio da análise de clusters. Foram analisadas todas as unidades de análise relativas à totalidade de aulas lecionadas, entendendo-se por unidade de análise qualquer interação professor-aluno ou, simplesmente, qualquer intervenção do aluno ou do professor, em determinado momento; na quinta etapa, foi feita a interpretação de todas as análises efetuadas nas etapas anteriores, de modo a dar resposta aos objetivos propostos.

\section{Resultados}

No total, foram identificados nove padrões de mediação diferentes (BRANCO, 2018a, p. 115-119; BRANCO, 2018c, p. 164-170), que denominamos de E1 a E9, de acordo com a sua qualidade e tendo em conta o esforço do professor, nomeadamente na introdução e utilização dos mediadores.

O padrão E1 é caracterizado pela solicitação de trabalho que requer a resposta a uma questão, geralmente resposta imediata, muitas vezes sem apresentação de qualquer situação física nem contextualização. Quando é mostrada situação física, o professor recorre à evocação ou a imagens e/ou a informações contidas em ficha de trabalho ou então a materiais e a contextualiza em torno de situações do dia a dia, do conhecimento do aluno. As práticas 
de ensino que ocorrem são, usualmente, práticas que, à partida, não promovem a ocorrência de práticas epistêmicas, como, a dispersão na abordagem de situações, o curto-circuito do trabalho dos alunos. Normalmente, não ocorre PE alguma. Quando isso acontece (muito pontualmente), são tipo 1, espontâneas e pouco consistentes, que o professor não aproveita. Pontualmente, o professor introduz mediadores (simbólico e/ou epistêmico), que também utiliza, não dando essa oportunidade aos alunos. Em geral, não ocorre PE alguma. Quando ocorrem, são únicas, pontuais e espontâneas. Apenas quando o professor solicita aspectos adicionais (muito raramente) se verifica a ocorrência de $2 \mathrm{PE}$, também espontâneas, que o professor não alimenta.

As PE verificadas, além da utilização limitada dos mediadores, são: PE1 (apresentação de ideia mobilizadora, identificação de condições empíricas, interpretação, questionamento factual).

O padrão E2 é caracterizado pela solicitação de trabalho que requer a análise de informação, com situação física apresentada através de imagens e/ou informação contidas em ficha de trabalho contextualizada em torno do ambiente natural e reconstruída em sala de aula, com intenção didática. O professor introduz mediador epistêmico, mas curto-circuita de imediato o trabalho solicitado aos alunos, não lhes dando oportunidade para se envolverem consistentemente em práticas epistêmicas. Geralmente, não ocorre PE alguma. Quando, eventualmente, os alunos utilizam os mediadores, fazem-no de modo muito limitado, pois o professor curto-circuita essa PE de imediato. Muito raramente se envolvem em uma única prática epistêmica tipo 1 que, não sendo devidamente alimentada pelo professor, acaba por não se repetir.

As PE verificadas, além da utilização limitada dos mediadores, são: PE1 (apresentação de ideia mobilizadora, interpretação).

O padrão E3 é caracterizado pela solicitação de trabalho que requer a observação de um fenômeno, geralmente com situação física contextualizada em torno de situações do dia a dia, do conhecimento do aluno, que o apresenta, recorrendo a material de laboratório. A prática de ensino mais comum é a introdução de mediadores (epistêmico e/ou simbólico) que o professor, ao usar, inibe ou limita essa mesma utilização pela parte dos alunos. Além do emprego limitado desses medidores, os alunos (eventualmente) apenas se envolvem em uma única prática epistêmica tipo 1, que ocorre de modo espontâneo, mas que o professor não alimenta convenientemente, curto-circuitando-a ou então a ignorando-a, passando a novo episódio. Quando o professor solicita aspectos adicionais (muito ocasionalmente) ocorrem, ainda que de modo pouco consistente, três PE tipo 1. Contudo, o professor continua a não alimentar devidamente essas práticas epistêmicas curto-circuitando-as, ou então dando o episódio por terminado.

As PE verificadas, além da utilização limitada dos mediadores, são: PE1 (apresentação de ideia mobilizadora, interpretação, manuseamento de equipamento de modo factual, questionamento factual).

O padrão E4 é caracterizado pela solicitação de trabalho que requer a resposta a uma questão, com situação física apresentada pela evocação, contextualizada em torno de situ- 
ações do dia a dia, do conhecimento do aluno. O professor introduz mediador epistêmico, que também utiliza, curto-circuitando o trabalho dos alunos. Quando os alunos usam o mediador epistêmico, fazem-no de modo muito limitado, pois o professor ou ignora essa prática epistêmica ou passa para novo episódio ou então retoma a prática de ensino já mencionada (curto-circuito). Espontânea e pontualmente os alunos ainda se envolvem entre 2 a 3 PE tipo 1, geralmente curto-circuitadas e/ou ignoradas pelo professor.

As PE verificadas, além da utilização limitada dos mediadores, são: PE1 (apresentação de ideia mobilizadora, identificação de condições empíricas, interpretação, manuseamento de equipamento de modo factual, questionamento factual).

O padrão E5 é caracterizado pela solicitação de trabalho que requer a resposta a uma questão, com situação física apresentada pela evocação, contextualizada em torno de situações do dia a dia, do conhecimento do aluno. O professor introduz mediadores (epistêmico ou simbólico), que utiliza pontualmente. Regularmente, o professor apresenta outras práticas de_ensino como o retomar práticas epistêmicas dos alunos reforçando a compreensão por meio de uma síntese ou de informação adicional; solicitar aspectos adicionais às respostas dos alunos para ampliar ou considerar novas perspectivas na abordagem da tarefa; valorizar epistemicamente. Os alunos se envolvem entre uma a cinco práticas epistêmicas, essencialmente de tipo 1. Pontualmente, se envolvem em PE tipo 2 e/ou tipo 3.

As PE verificadas, além da utilização ou introdução de mediadores são: PE1 (apresentação de ideia mobilizadora, interpretação, manuseamento de equipamento de modo factual, observar, procurar e selecionar informação); PE2 (conceitualização, mudança da representação do formato, questionamento conceitual); PE3 (comunicação autônoma).

O padrão E6 é caracterizado pela solicitação de trabalho que requer a resposta a uma questão ou análise de informação, com situação física apresentada pela evocação ou por meio de descrições orais e/ou escritas, contextualizada em torno do ambiente natural e reconstruído em ambiente escolar com intenção didática. Quando o professor introduz mediador epistêmico, não o utiliza. A prática de ensino mais verificada é a solicitação de aspectos adicionais às respostas dos alunos de forma a clarificar as práticas epistêmicas que ocorrem. Pontualmente, o professor retoma práticas epistêmicas dos alunos reforçando a compreensão por intermédio de uma síntese ou de informação adicional. Os alunos se envolvem entre duas a cinco práticas epistêmicas de tipo 1 e de tipo 2 e, mais raramente, de tipo 3.

As PE verificadas, além da utilização ou introdução de mediadores, quando existem, são: PE1 (identificação de condições empíricas, interpretação, procura e seleção de informação, questionamento factual); PE2 (comunicação não autônoma, conceptualização, mudança da representação do formato, estabelecimento de relações); PE3 (comunicação autônoma).

O padrão E7 é caracterizado pela solicitação de trabalho que requer a análise de informação, com situação física apresentada pela evocação ou por meio de descrições orais e/ou escritas, contextualizada em torno do ambiente natural e reconstruído em ambiente escolar com intenção didática. $\mathrm{O}$ professor solicita sempre aspectos adicionais às respostas dos alunos, de forma a clarificar as práticas epistêmicas que ocorrem. Pontualmente, intro- 
duz mediadores (epistêmicos ou simbólicos), que não utiliza e apresenta outras práticas de ensino como a solicitação de aspectos adicionais às respostas dos alunos para ampliar ou considerar novas perspectivas na abordagem da tarefa, explicita epistemicamente ou então retoma as práticas epistêmicas dos alunos, reforçando a compreensão por intermédio de uma síntese ou de informação adicional. Os alunos se envolvem entre uma a sete práticas epistêmicas dos três tipos.

As PE verificadas, além da utilização de mediadores (mais associados a PE tipo $1 \mathrm{e}$ tipo 2) são: PE1 (identificação de condições empíricas, interpretação, manuseamento de equipamento de modo factual, procura e seleção de informação); PE2 (comunicação não autônoma, conceptualização, mudança da representação do formato, estabelecimento de relações); PE3 (comunicação autônoma e, mais raramente, avaliação crítica.

O padrão E8 é caracterizado pela solicitação de trabalho que requer a elaboração de uma resposta, com situação física apresentada por intermédio de objetos ou equipamentos, contextualizada em torno do ambiente natural e reconstruído em ambiente escolar com intenção didática. O professor apresenta continuamente práticas de ensino diversificadas. Além de introduzir mediadores epistêmicos que não utiliza, solicita aspectos adicionais às respostas dos alunos, de forma a clarificar as práticas epistêmicas que ocorrem ou então para ampliar ou considerar novas perspectivas na abordagem da tarefa, explicita epistemicamente, valoriza epistemicamente e retoma práticas epistêmicas dos alunos reforçando a compreensão por meio de uma síntese ou de informação adicional. Os alunos se envolvem entre sete a dez práticas epistêmicas dos três tipos.

As PE verificadas, além da utilização ou introdução de mediadores associados a PE dos três tipos são: PE1 (identificação de condições empíricas, interpretação, manuseamento de equipamento de modo factual, observação, procura e seleção de informação, questionamento factual); PE2 (comunicação não autônoma, conceptualização, mudança da representação do formato, estabelecimento de relações, questionamento conceitual); PE3 (comunicação autônoma, avaliação crítica).

O padrão E9 é caracterizado, geralmente, pela solicitação de trabalho que requer a elaboração de uma resposta, com situação física apresentada por intermédio de objetos ou equipamentos, contextualizada em torno do ambiente natural e reconstruído em ambiente escolar com intenção didática. $\mathrm{O}$ professor solicita sempre aspectos adicionais às respostas dos alunos, de forma a clarificar as práticas epistêmicas que ocorrem. Pontualmente, introduz mediadores epistêmicos, que só utiliza para continuar a alimentar as práticas epistêmicas que ocorrem. Regularmente, o professor exibe outras práticas de ensino, como a solicitação de aspectos adicionais às respostas dos alunos para ampliar ou considerar novas perspectivas na abordagem da tarefa, explicita epistemicamente, valoriza epistemicamente, ou então retoma práticas epistêmicas dos alunos, reforçando a compreensão por meio de uma síntese ou de informação adicional. Os alunos se envolvem entre três a nove práticas epistêmicas dos três tipos.

As PE verificadas, além da utilização ou introdução de mediadores (mais associados a PE de tipo 1 e de tipo 2), são: PE1 (apresentação de ideia mobilizadora, identificação 
de condições empíricas, interpretação, manuseamento de equipamento de modo factual, observação, procura e seleção de informação, questionamento factual); PE2 (comunicação não autônoma, conceptualização, mudança da representação do formato, estabelecimento de relações, manuseamento de equipamento de modo conceptual, questionamento conceptual); PE3 (comunicação autônoma e, mais raramente, avaliação crítica).

O padrão de mediação E9 apresenta qualidade superior ao padrão de medição E8, quer pelo tipo de PE quer pelo esforço do professor, nomeadamente na introdução e utilização de mediadores epistêmicos.

Do processamento dos resultados do estudo, constata-se que, dos nove padrões identificados, ocorreram cinco padrões de mediação na $1^{\text {a }}$. fase (E1, E2, E3, E4 e E9), quatro na $2^{\mathrm{a}}$. fase (E6, E7, E8 e E9) e três na $3^{\mathrm{a}}$ fase (E5, E6 e E9). Após a elaboração e análise dos dendrogramas obtidos por meio do programa STATISTICA (Statsoft ${ }^{\circledR}$ ) foram verificados, nas três fases do estudo, os padrões de mediação constantes na Figura 1.

Figura 1 - Padrões de mediação verificados durante as três fases do estudo.
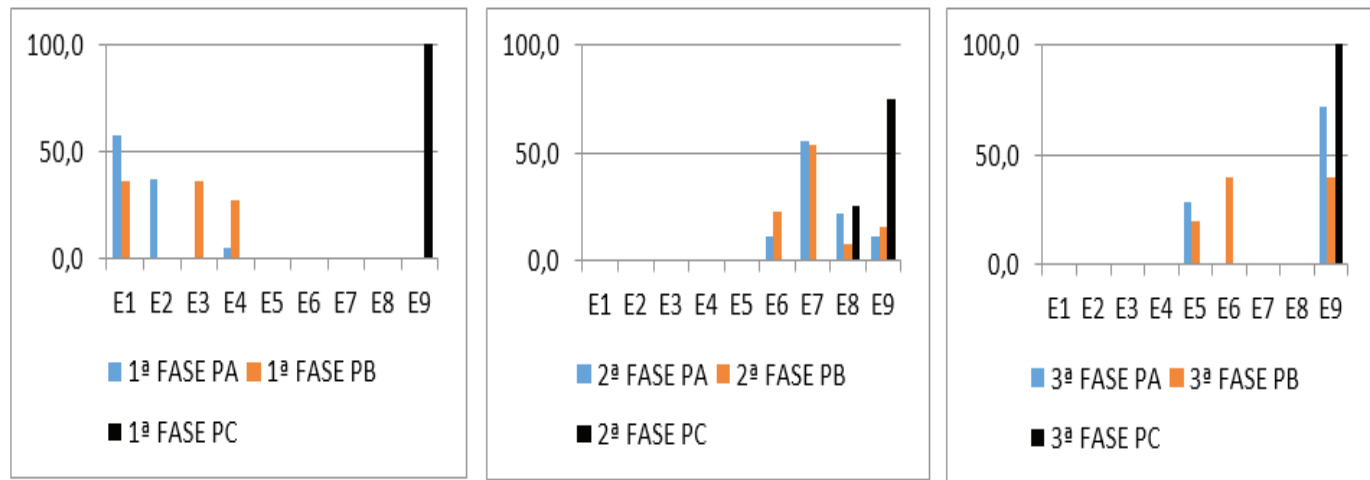

Tendo em conta que os padrões de mediação E1 a E4, que diferem essencialmente no tipo e modo de apresentação do trabalho pelo professor, são os de menor qualidade, não promovendo $\mathrm{PE}$ nos alunos ou então promovendo apenas $\mathrm{PE}$ espontâneas, pontuais e pouco consistentes; o padrão de mediação $\mathrm{E} 5$, que ocorre em trabalho que requer a resposta a uma questão onde o professor exibe pontualmente práticas de ensino promotoras de PE, bem como, a introdução (e utilização pontual) de mediadores, ainda que sendo de curta duração promove essencialmente PE tipo 1; os padrões E6 a E9 que diferem, essencialmente, no tipo de trabalho solicitado (resposta a uma questão, análise de informação ou elaboração de uma resposta), na diversidade e persistência de práticas de ensino promotoras de práticas epistêmicas ou na duração temporal do episódio, promovem uma maior diversidade e frequência de PE nos alunos; o padrão E9 é o de maior qualidade tanto em termos da qualidade de PE como nos esforços que o professor faz na introdução e utilização de mediadores, constatou-se o seguinte: 
Como era expectável, o professor $\mathrm{C}$ apresentou padrões de mediação mais consistentes e mais eficazes na promoção de práticas epistêmicas nos seus alunos. Nas três fases do estudo, exibiu maioritariamente o padrão $\mathrm{E} 9$, sendo este o padrão verificado na totalidade dos episódios da $1^{\mathrm{a}}$. e $3^{\mathrm{a}}$. fase do estudo. Apenas na $2^{\mathrm{a}}$. fase do estudo mostrou $25 \%$ dos episódios com o padrão E8. Esse professor promoveu sempre nos seus alunos PE diversificadas e dos diferentes tipos. Solicitou, preferencialmente, trabalho que requeria a elaboração de uma resposta, geralmente com situações físicas expostas por meio de objetos e reconstruídas em ambiente escolar, com intenção didática. $\mathrm{O}$ professor $\mathrm{C}$ alimentou continuamente as PE dos alunos (dos três níveis), solicitando aspectos adicionais ao trabalho apresentado e às PE dos alunos, valorizando-as e as explicitando epistemicamente e as retomando, por vezes, para reforçar a sua compreensão por intermédio de breve síntese ou de informação adicional. Com esses padrões de mediação os alunos tanto se envolveram em PE tipo 1 (identificação de condições empíricas, manuseamento de equipamento factual, interpretação, questionamento factual, organização de informação, observação, apresentação de ideia mobilizadora), como PE tipo 2 (mudança de representação de formato, conceitualização, comunicação não autônoma, questionamento conceitual, manuseamento de equipamento de modo conceitual, estabelecimento de relações) e PE tipo 3 (comunicação autônoma, avaliação crítica). Relativamente aos mediadores (epistêmicos e simbólicos), esse professor apenas os utilizou para solicitar aspectos adicionais às respostas dos alunos, no sentido de clarificá-las ou então deu total autonomia do seu uso aos alunos que o fizeram associado à $\mathrm{PE}$ dos diferentes tipos.

Os professores A e B, na $1^{\mathrm{a}}$. fase, apenas apresentaram os padrões de menor qualidade, não promovendo PE nos seus alunos. Ainda que o tipo de trabalho solicitado tenha variado entre a solicitação de resposta a uma questão, a análise de informação ou a observação, o modo como o professor o encaminhava na sala de aula, ou seja, a sua mediação, inibia a ocorrência dessas práticas. Nesses padrões, verificou-se que as práticas de ensino desses professores consistiam essencialmente: i) no não aproveitamento de ideias, questões ou iniciativas dos alunos para promover PE, ignorando de forma epistêmica; ii) na expressão da sua concepção epistêmica, desvalorizando as possíveis PE dos alunos, ou seja, desvalorizando de forma epistêmica; iii) na ausência de oportunidade dada aos alunos para executarem o trabalho solicitado ou para desenvolverem PE, encaminhando-os apenas para a resolução de aspectos mecânicos, "curto-circuitando" o trabalho solicitado ou em curso; iv) não se centrando num número manejável de situações físicas, dispersando-se na abordagem das mesmas, ou então v) não dando tempo de resposta aos alunos, solicitando imediatamente novo trabalho.

Ilustra-se o padrão E1 com um excerto da $2^{\mathrm{a}}$. tarefa da $1^{\mathrm{a}}$. aula do professor B (tarefa que requer a resposta a uma questão), na $1^{\mathrm{a}}$. fase do estudo:

"O professor escreveu a $2^{\mathrm{a}}$. questão no quadro "A luz propaga-se em todos os meios?"

- Ora bem, nós vamos ter que apagar a luz porque eu coloquei ali uma questão no quadro que era se a luz se propagava em todos os meios. Nós vimos que o 
som se propagava nos sólidos, nos líquidos e nos gases, disse o professor, enquanto os alunos escureceram totalmente a sala.

- Olhem agora para aqui - continuou o professor, enquanto colocava entre uma vela acesa e os alunos, um livro - se eu colocar este livro assim, vocês não conseguem ver a vela através do livro - afirmou. E agora? "Questionou, enquanto retirava o livro que estava colocado à frente da vela acesa."

Nesse excerto, verifica-se que, apesar de o professor ter introduzido um mediador epistêmico, acabou por usá-lo de modo a não permitir que os alunos o fizessem, "curto-circuitando" imediatamente a tarefa apresentada, não promovendo qualquer PE.

Quando esses professores tomaram consciência das suas práticas de ensino e das repercussões que tinham na promoção de práticas epistêmicas pelos seus alunos, sentiram grande vontade e necessidade de refletir sobre as mesmas no sentido de melhorá-las. Essas reflexões foram suportadas na análise das suas NM. Por intermédio das NM, tomaram consciência dos aspectos (ou traços) das suas mediações que não surtiam o efeito desejado. As NM serviram como um espelho das suas aulas. Foram o elemento catalisador para a tomada de consciência das mudanças que tinham de realizar. Os elementos impulsionadores dessa mudança foram as ferramentas de ajuda. Ou seja, a melhoria das práticas de ensino verificadas na $2^{\mathrm{a}}$. e $3^{\mathrm{a}}$. fase, com a ocorrência de padrões de mediação de nível mais elevado, próximos dos padrões de mediação do professor $\mathrm{C}$, assentou num processo de reflexão mobilizada pela articulação das NM com as ferramentas de ajuda (BRANCO, 2018b).

Ilustramos o padrão E9 com a $1^{\mathrm{a}}$. tarefa apresentada pelo professor A na $1^{\mathrm{a}}$. aula da $3^{\mathrm{a}}$. fase do estudo, onde o professor solicitou aos alunos a dedução das leis da reflexão e as características das imagens obtidas através dos espelhos planos, tendo disponibilizado o material pertinente para a exequibilidade da tarefa proposta. O trabalho solicitado, consistindo na elaboração de uma resposta, foi exibido por meio de uma ficha de trabalho que o professor distribuiu aos alunos, por grupo de trabalho, tendo o cuidado de previamente ter colocado na mesa de trabalho o material adequado:

O professor solicitou a leitura da tarefa constante na ficha de trabalho, em voz alta. O Ivo voluntariou-se para o efeito. Quando questionados sobre a existência de dúvidas sobre o trabalho a realizar, os alunos responderam terem entendido a tarefa proposta. Imediatamente deram início à atividade experimental, utilizando o material necessário, disponibilizado previamente pelo professor (laser, espelho plano, disco graduado, folhas de papel branco, vela. Os alunos dos três grupos fazem incidir sobre o espelho o laser que colocam em cima do disco, em várias posições, registrando as suas observações e tentando traçar a lápis numa folha de papel branco, que colocaram em cima do disco, o percurso do laser, sem recorrerem à régua.

Nesse pequeno excerto, verifica-se a evolução positiva desse professor na escolha da tarefa e no seu encaminhamento durante a aula. Apesar de ter introduzido um mediador epistêmico, não o utilizou. Promoveu nos alunos PE diversificadas e continuadas ao longo da realização de toda a tarefa. Os alunos usaram o mediador epistêmico, manuseando o 
equipamento de modo factual, observando e fazendo a representação simbólica do que observaram. Surgiram questionamentos factuais relativos à tarefa e à solicitação de aspectos adicionais, pelo professor, de forma a clarificar essas PE.

\footnotetext{
No grupo 1:

A Catarina afirma não haver nenhuma relação entre os ângulos. Não está a entender a questão. Os restantes elementos do grupo não concordam com essa opinião. Entretanto, o Domingos começa a identificar a normal nas várias situações experimentadas enquanto a Bruna e a Ana $\mathrm{G}$ concluem que os ângulos são iguais.
}

Nesse excerto, constata-se ainda a interpretação do esquema realizado pelos alunos, usando o conhecimento científico. A continuação de solicitação de aspectos adicionais a essas PE pelo professor continuou a promover PE continuamente, nomeadamente novas representações simbólicas das observações efetuadas, conceitualizando e mudando o formato da representação, bem como, a comunicação desses resultados, tanto de forma autônoma como não autônoma.

A discussão desses resultados será apresentada na seção que se segue.

\section{Discussão}

Foram identificados nove padrões de mediação, com repercussões diferentes na promoção de práticas epistêmicas nos alunos.

Verificou-se que quando o professor transforma o trabalho solicitado num conjunto de pedidos sucessivos de exemplos não explorados, não se centrando num número manejável de situações físicas, dispersa-se na abordagem das mesmas ou encaminha os alunos apenas para os aspectos mecânicos das tarefas exibidas: não permite que os alunos se envolvam em atividades sociais de produção, comunicação e avaliação do conhecimento científico (KELLY, 2005; KELLY et al., 2012). Esses padrões (E1 a E4) foram verificados nas aulas dos professores A e B durante a $1^{\mathrm{a}}$. fase do estudo.

Quando esses professores foram confrontados com esses resultados, baseando-se na análise das suas NM, sentiram necessidade de melhorar as suas práticas de ensino de modo a evoluírem para padrões de mediação de maior qualidade (E5 a E9), tentando aproximar-se do padrão de mediação do professor C (E9), cujas práticas de ensino serviram de referência. Essa evolução foi suportada num processo de reflexão mobilizada pela articulação das NM com as ferramentas de ajuda (BRANCO, 2018b), bem como, no ciclo de investigação-ação verificado na $2^{\mathrm{a}}$. fase. Ainda que a $3^{\mathrm{a}}$. fase tenha decorrido com metodologia semelhante à da $1^{\text {a }}$. fase, sem intervenção do investigador, os professores A e B conseguiram manter os padrões verificados na $2^{\mathrm{a}}$. fase, recorrendo durante esse ano aos instrumentos disponibilizados na fase anterior (LOPES et al., 2012) por vontade própria e de acordo com as suas necessidades.

As NM serviram de ponto de partida para reflexões formadas (e informadas) a partir das suas próprias práticas de ensino. Impulsionaram nesses professores a vontade e necessidade 
para a mudança das suas mediações, tendo em conta a promoção de práticas epistêmicas nos seus alunos. Quando confrontados com os resultados obtidos na $1^{\mathrm{a}}$. fase, os professores A e B deram outra relevância à importância das tarefas apresentadas, aos recursos fornecidos para a exequibilidade das mesmas, assim como às suas interações em sala de aula, de modo a levar os alunos a se envolverem em PE. Os professores A e B deixaram de apresentar as práticas de ensino descritas na $1^{\mathrm{a}}$. fase e passaram a dar mais autonomia aos alunos, bem como, mais tempo de resposta às tarefas exibidas, cujo número por aula diminuiu consideravelmente. Passaram a: 1) solicitar, com grande frequência, aspectos adicionais às respostas dos alunos no sentido de clarificar as PE que ocorriam ou então para ampliar ou considerar novas perspectivas na abordagem do trabalho solicitado; 2) retomar PE dos alunos, reforçando a sua compreensão por meio de sínteses ou de informações adicionais; 3) explicitar-se de forma epistêmica; 4) aproveitar ideias, esquemas ou ações dos alunos reconhecendo-lhes valor epistêmico. Essa mudança de padrões de mediação promoveu nos alunos PE tanto de tipo 1 (questionamento factual, organização de informação, manuseamento de material de modo factual, interpretação, observação, apresentação de ideia mobilizadora, identificação de condições empíricas), como de tipo 2 (questionamento concetual, comunicação não autônoma, representação simbólica, estabelecimento de relações, manuseamento de equipamento de modo concetual, mudança de uma representação para outra) e tipo 3 ( comunicação autônoma, avaliação crítica, validação de conhecimento). A evolução desses padrões de mediação também se repercutiu no modo de utilização dos mediadores quer por parte do professor, quer por parte do aluno. Quando o professor os usava, fazia-o para "alimentar" as PE dos alunos que, por sua vez, os utilizaram associados não somente a PE tipo 1 como também a PE tipo 2 e tipo 3.

\section{Considerações finais}

Com este trabalho, conclui-se que os padrões de mediação dos professores têm repercussões bastantes pertinentes nas aprendizagens dos alunos, nomeadamente na promoção de práticas epistêmicas. Conclui-se também que a tarefa apresentada, os recursos disponibilizados, o modo como o professor conduz a tarefa e os mediadores em sala de aula são determinantes para que essas práticas de ensino ocorram de uma forma mais eficaz. Verifica-se ainda que o recurso às NM das suas aulas é crucial para promover a reflexão assertiva dos professores acerca das suas práticas de ensino, bem como, para despoletar a necessidade de as melhorarem.

\section{REFERÊNCIAS}

ALARCÃO, I. (1996). Reflexão crítica sobre o pensamento de D. Schön e os programas de formação de professores. Revista da Faculdade de Educação, 22 (2), 11-42.

BRANCO, M. J. (2018,a). Desenvolvimento das práticas de mediação dos professores em contexto de ensino de Ciências Físicas - $\mathrm{O}$ papel de ferramentas de ajuda, $\mathrm{PhD}$ Thesis, Universidade de Trás-os-Montes e Alto Douro, Vila Real. 
BRANCO, M. J. (2018,b). Melhoria de práticas de ensino de C \& T ao longo do tempo recorrendo a um processo de reflexão assente na mobilização articulada de Narrações Multimodais com ferramentas de ajuda. In: LOPES, J. B., VIEGAS, C., \& PINTO, A. (Orgs.), Melhorar Práticas de Ensino de Ciências e Tecnologia (p. 213-226). Edições Sílabo, Portugal.

BRANCO, M. J. (2018,c). Desenvolvendo práticas de ensino promotoras de aprendizagens eficazes - Um Modelo de Desenvolvimento Profissional baseado em Reflexões assentes em Narrações Multimodais e Ferramentas de Ajuda. Novas Edições Académicas, Germany.

BRANCO, M. J. (2017). The Role of Tools to Aid Teacher Mediation in Teacher Professional Development. In: LOPES, J. B., CRAVINO, J. P., CRUZ, E. S., \& BARBOT, A. (Orgs.), Teacher Science: Contributions of Research for Planning, Practice and Professional Development (p. 355-372). Nova Science Publishers, New York.

BRANCO, M. J., MAGALHÃES, R., FERREIRA, A., LOPES, J. B., \& CRAVINO, J. P. (2009). Narrações de aulas: um estímulo ao desenvolvimento profissional? In: PAIXÃO, F \& F. R. JORGE (Orgs.), Actas do XIII Encontro Nacional de Educação Científica (p. 740-749). Castelo Branco: Instituto Politécnico de Castelo Branco.

BREDESON, P. V. (2002). The architecture of professional development: Materials, messages and meaning. International Journal of Educational Research, 37 (8), 661-675.

BUTLER, D. L., LAUSCHER, H. N., JARVIS-SELINGER, S., \& BECKINGHAM, B. (2004). Collaboration and self-regulation in teachers' professional development. Teaching and Teacher Education, 20 (5), 435-455.

COHEN, L., MANION, L., \& MORRISON, K. (2013). Research Methods in Education. Routledge.

CRAWFORD, T., KELLY, G. J., \& BROWN, C. (2000). Ways of Knowing beyond Facts and Laws of Science: An Ethnographic Investigation of Student Engagement in Scientific Practices. Journal of Research in Science Teaching, 37 (3), 237-258.

DANISH, J. A., \& ENYEDY, N. (2007). Negotiated representational mediators: How young children decide what to include in their science representations. Science Education, $91(1), 1-35$.

GILLENTINE, J. (2006). Understanding early literacy development: The impact of narrative and reflection as tools within a collaborative professional development setting. Journal of Early Childhood Teacher Education, 27 (4), 343-362.

KELLY, G. J. (2005). Inquiry, Activity, and Epistemic Practice. Paper presented at the Inquiry Conference on Developing a Consensus Research Agenda. New Brunswick, NJ.

KELLY, G. J., MCDONALD, S., \& WICKMAN, P. O. (2012). Science learning and epistemology. In: Second international handbook of science education (p. 281-291). Springer Netherlands. 
KNUUTTILA, T. (2005). Models, Representation, and Mediation. Philosophy of Science, 72 (5), 1.260-1.271.

LOPES, J. B., BRANCO, M. J., \& JIMÉNEZ-ALEIXANDRE (2011). 'Learning Experience' Provided by Science Teaching Practice in a Classroom and the Development of Students' Competences. Research in Science Education, 41 (5), 787-809.

LOPES, J. B., CRAVINO, J. P., BRANCO, M., SARAIVA, E., \& SILVA, A. A. (2008). Mediation of student learning: dimensions and evidences in science teaching. PEC 2008 Problems of Education in the 21st Century, 9, 42-52.

LOPES, J. B., CRAVINO, J. P., \& SILVA, A. A. (2010a). A Model for Effective Teaching in Science and Technology (Metilost). New York: Nova Science Publishers, Inc.

LOPES, J. B., SIlVA, A. A., CRAVINO, J. P., SANTOS, C. A., CUNHA, A. E., PINTO, A., SILVA, A., VIEGAS, C., SARAIVA, E., BRANCO, M. J. (2014). Constructing and Using Multimodal Narratives to Research in Science Education: Contributions Based on Practical Classroom. Research in Science Education, 44 (3), 415-438.

LOPES, J. B., SILVA, A. A., CRAVINO, J. P., VIEGAS, C., CUNHA, A. E., SARAIVA, E., BRANCO, M. J., PINTO, A., SILVA, A., SANTOS, C. A. (2012). Instrumentos de ajuda à mediação do professor para promover a aprendizagem dos alunos e o desenvolvimento profissional dos professores. Sensos, 2 (1), 125-171.

LOPES, J. B., SIlVA, A. A., CRAVINO, J. P., VIEGAS, C., CUNHA, A. E., SARAIVA, E., BRANCO, M. J., PINTO, A., SILVA, A., \& SANTOS, C. A. (2010b). Investigação sobre a Mediação de Professores de Ciências Físicas em sala de aula. Universidade de Trás-os-Montes e Alto Douro. Minerva Transmontana, Tipografia, Lda. Vila Real.

RADFORD, L. (2012). On the Cognitive, Epistemic, and Ontological Roles of Artifacts. In: G. GUEUDET, L. TROUCHE \& B. PEPIN (Orgs.), From Text to 'Lived' Resources: Mathematics Curriculum Materials and Teacher Development (v. 238-288, p. 283). Netherlands: Springer.

REVELES, J., KELLY, G., \& DURÁN, R. (2007). A sociocultural perspective on mediated activity in third grade science. Cultural Studies of Science Education, 1 (3), 467-495.

SACRISTÁN, J. G. (1988). El curriculum: una reflexión sobre la práctica (v. 1). Madrid: Morata.

SCHÖN, D. (1983). The reflective practioner. London: Basic Books.

SCOTT, P. H., MORTIMER, E. F., \& AGUIAR, O. G. (2006). The tension between authoritative and dialogic discourse: A fundamental characteristic of meaning making interactions in high school science lessons. Science Education, 90 (4), 605-631.

STAKE, R. E. (2013). Multiple case study analysis. New York: Guilford Press. 
WILSON, A. A. (2013). A typology of actional operational modes in earth science and implications for science literacy instruction. Science Education, 97 (4), 524-549.

WU, H.-K., \& PUNTAMBEKAR, S. (2012). Pedagogical affordances of multiple external representations in scientific processes. Journal of Science Education and Technology, 21 (6), 754-767.

\section{DAdOS DA AUTORA:}

Maria Júlia Branco

Doutora em Didática de Ciências e Tecnologia, na especialidade de Didática de Ciências Físicas. Professora de Física e Química na Escola Secundária de Póvoa de Lanhoso. Portugal. litabranco@gmail.com

Submetido em: 4-12-2018

Aceito em: 26-3-2019 